\title{
Isothiourea-Mediated Organocatalytic Michael Addition- Lactonization on a Surface: Modification of SAMs on Silicon Oxide Substrates
}

\author{
Ross Chisholm, John D. Parkin, Andrew D. Smith,* and Georg Hähner* \\ EaStCHEM School of Chemistry, University of St. Andrews, North Haugh, St. Andrews KY16 9ST, U.K.
}

Supporting Information

ABSTRACT: Tailoring the functionality of self-assembled monolayers (SAMs) can be achieved either by depositing prefunctionalized molecules with the appropriate terminal groups or by chemical modification of an existing SAM in situ. The latter approach is particularly advantageous to allow for diversity of surface functionalization from a single SAM and if the incorporation of bulky groups is desired. In the present study an organocatalytic isothiourea-mediated Michael addition-lactonization process analogous to a previously reported study in solution is presented. An achiral isothiourea, 3,4dihydro-2H-pyrimido[2,1-b] benzothiazole (DHPB), promotes

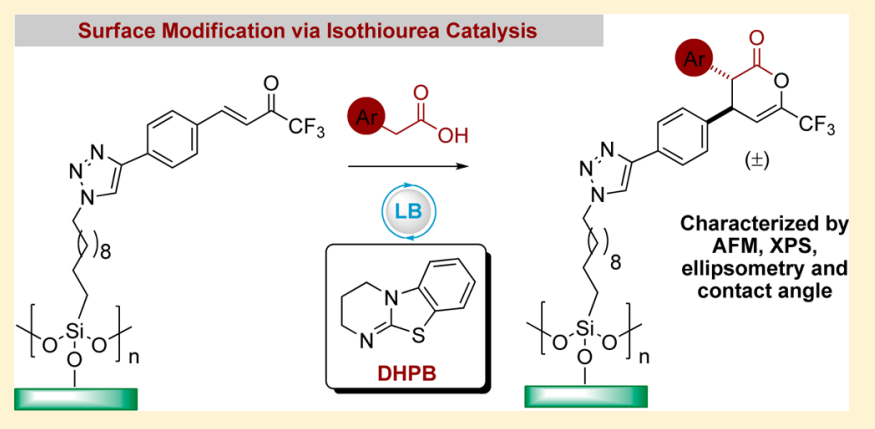
the intermolecular Michael addition-lactonization of a trifluoromethylenone terminated SAM and a variety of arylacetic acids affording C(6)-trifluoromethyldihydropyranones tethered to the surface. X-ray photoelectron spectroscopy, atomic force microscopy, contact angle, and ellipsometry analysis were conducted to confirm the presence of the substituted dihydropyranone. A model study of this approach was also performed in solution to probe the reaction diastereoselectivity as it cannot be measured directly on the surface.

\section{INTRODUCTION}

The functionalization of solid surfaces by means of selfassembled monolayers (SAMs) has become an active area of research since their first report by Sagiv in $1980 .{ }^{1}$ One particular class of molecules that has attracted significant attention are silanes on hydroxyl terminated substrates. ${ }^{2}$ Silanebased SAMs offer a significant advantage compared to their thiol on Au counterparts, in that they possess a stronger bond to the surface that allows a greater range of operation conditions in any further process. ${ }^{3-5}$ Typically a silane-based SAM is constructed from a suitable alkylsilane precursor where the reactive headgroup consists of trichlorosilane $\left(\mathrm{R}-\mathrm{SiCl}_{3}\right)$, trimethoxysilane $\left(\mathrm{R}-\mathrm{Si}(\mathrm{OMe})_{3}\right)$, or triethoxysilane $(\mathrm{R}-\mathrm{Si}$ $\left.(\mathrm{OEt})_{3}\right){ }^{6}$ The suitable precursor can be deposited on the surface using either solution ${ }^{7}$ or vapor ${ }^{8,9}$ phase methodology. Such silane-based SAMs can be formed on any silica-based substrate such as glass, ${ }^{10}$ mica, ${ }^{11}$ and quartz. ${ }^{12}$ These systems are physically, ${ }^{13,14}$ thermally, ${ }^{15,16}$ and chemically ${ }^{2}$ stable and can be applied in various fields of bio- and nanotechnology, e.g., electronics, ${ }^{17}$ sensors, ${ }^{18-20}$ and micro- and nanoelectromechanical systems (MEMS and NEMS). ${ }^{21}$ MEMS and NEMS are typically made of silicon and are increasingly finding applications as pressure and acceleration sensors, linear actuators, or valves. ${ }^{21}$ The operating environments of MEMS and NEMS mean that they often require a chemical modification of the silicon surface to ensure a reliable operation. SAMs are central in this task because they provide a route for direct chemical modification of the structures and for modification of deposited monolayers in situ. ${ }^{3-5,22}$ In situ modification of SAMs offer an attractive approach to surface functionalization as a large variety of different organic reactions can be used to tailor toward a desired surface property. ${ }^{5}$ Owing to their thermal and chemical stability, a broad range of chemical reactions can be applied to silane-based SAMs such as nucleophilic substitution, ${ }^{23}$ reduction reactions, ${ }^{24}$ supramolecular modification, ${ }^{25}$ and click chemistry. ${ }^{26,27}$ The latter can build upon a molecular framework that is already in place, and structured molecular layers can be constructed from a bottomup approach. One of the most well-known click reactions is the Huisgen 1,3-dipolar cycloaddition that involves the reaction of an azide with an alkyne in the presence of a copper catalyst affording the corresponding 1,2,3-triazole. ${ }^{28}$ The approach of using click chemistry to functionalize a surface has the advantage of being able to introduce bulky groups that may otherwise be difficult using classical organic synthesis methods. Building on the success of using click chemistry in the literature, we have pursued an alternative approach to surface functionalization. Our approach utilizes established click chemistry to generate a common reactive Michael acceptor on a $\mathrm{Si} / \mathrm{SiO}_{2}$ surface and uses a subsequent catalytic late-stage Michael addition-lactonization process using Lewis base

Received: December 22, 2015

Revised: $\quad$ March 14, 2016

Published: March 25, 2016 
organocatalysis to generate a small library of dihydropyranones on the surface.

Organocatalysis has now become one of the main methods for selective carbon-carbon bond formation and has received much attention over the past decade. ${ }^{29,30}$ Within the realm of organocatalysis the mode of action of the catalyst can generally be separated into four classes, namely Brønsted base, Brønsted acid, Lewis acid, and Lewis base catalysis. ${ }^{31}$ Pioneered by Romo in 2001, the nucleophile-catalyzed aldol/lactonization (NCAL) reaction demonstrates that ammonium enolates can be readily generated and used in enantioselective reaction processes. ${ }^{32}$ In this approach the catalytic generation of $C(1)$-ammonium enolates is achieved using a Lewis basic tertiary amine and readily available, bench-stable precursors at the carboxylic acid oxidation level. ${ }^{33}$ Previous work in our group has demonstrated that isothioureas can catalytically promote the intermolecular Michael lactonization of arylacetic acids and trifluoromethylenones in the presence of pivaloyl chloride (to form a reactive in situ mixed anhydride), giving $\mathrm{C}(6)$-trifluoromethyldihydropyranones in solution. ${ }^{33}$ We envisaged that this methodology could be applied to the late-stage functionalization of selfassembled monolayers in situ as summarized in Figure 1.

Previous studies in solution:

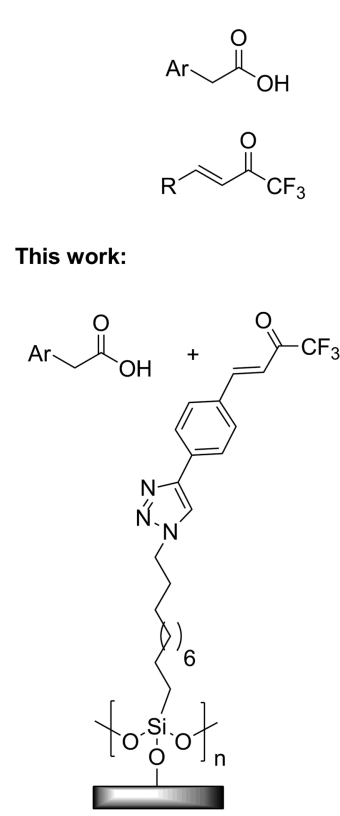

$$
\begin{aligned}
& \text { i) }\left(\mathrm{CH}_{3}\right)_{3} \mathrm{CCOCl}(1.5 \mathrm{eq}) \\
& \text { i- } \mathrm{Pr}_{2} \mathrm{NEt}(1.5 \mathrm{eq}) \\
& \text { ii) } \mathrm{HyperBTM}(5 \mathrm{~mol} \%) \\
& \text { i- } \mathrm{Pr}_{2} \mathrm{NEt}(2.5 \mathrm{eq}) \\
& \underset{\mathrm{CH}_{2} \mathrm{Cl}_{2},-78^{\circ} \mathrm{C}, 16 \mathrm{~h}}{\longrightarrow}
\end{aligned}
$$
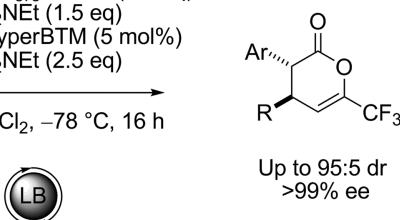

Up to $95: 5 d r$ $>99 \%$ ee

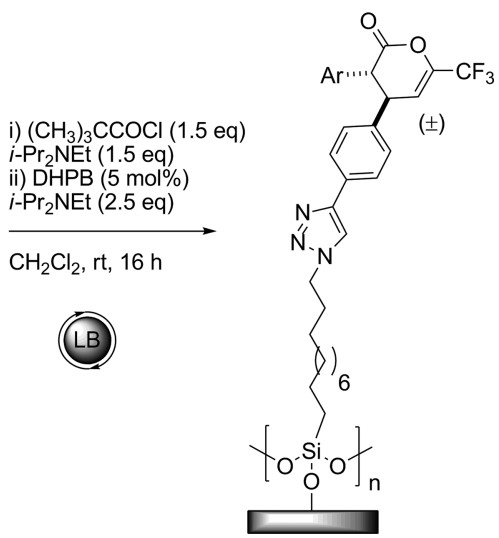

Figure 1. Summary of previous solution chemistry and the analogous surface chemistry explored in this work.

Numerous examples of using solid supports to anchor or tether organocatalysts to the surface exist in the literature, ${ }^{34-37}$ but to the best of our knowledge using organocatalysis to immobilize a reactive species onto a surface has not been explored.

In this article we report a route for the organocatalytic in situ modification of trifluoromethylenone terminated SAMs that allows the direct late-stage formation of functionalized trifluoromethyldihydropyranones on a $\mathrm{Si} / \mathrm{SiO}_{2}$ surface. The organocatalytic Michael addition-lactonization process was studied by X-ray photoelectron spectroscopy (XPS), atomic force microscopy (AFM), contact angle goniometry (CA), and variable angle spectroscopic ellipsometry.

\section{EXPERIMENTAL DETAILS}

Reagents. Silicon wafers (P/Boron Si, Shin-Etsu Handotai Europe Ltd., Livingstone, UK) were cut into approximately $1.0 \times 1.5 \mathrm{~cm}^{2}$ sized pieces. 11-Bromoundecyltrichlorosilane (Fluorochem, UK), sodium azide (Sigma-Aldrich, UK), all arylacetic acids (Alfa Aesar, $\mathrm{UK}$ ), $\mathrm{CuSO}_{4} \cdot 5 \mathrm{H}_{2} \mathrm{O}$ (Acros, UK), (+)-sodium ascorbate (SigmaAldrich, UK), EtOH (Sigma-Aldrich, UK), and DMF (Sigma-Aldrich, $\mathrm{UK})$ were used as received. Dichloromethane $\left(\mathrm{CH}_{2} \mathrm{Cl}_{2}\right)$ was obtained dry from a solvent purification system (MBraun, SPS-800).

Pretreatment of Silicon Wafers. The silicon wafers were placed in a solution of concentrated $\mathrm{H}_{2} \mathrm{SO}_{4}(98 \%)$ and $\mathrm{H}_{2} \mathrm{O}_{2}(30 \% \mathrm{v} / \mathrm{v})(2: 1)$ at $70{ }^{\circ} \mathrm{C}$ for $15 \mathrm{~min}$. (Caution: "piranha" solution reacts violently with many organic materials and should be handled with care!) The wafer was then placed in a solution of concentrated $\mathrm{NH}_{4} \mathrm{OH}$, DI water and $\mathrm{H}_{2} \mathrm{O}_{2}$ $(30 \% \mathrm{v} / \mathrm{v})(1: 5: 1)$ at $70{ }^{\circ} \mathrm{C}$ for $15 \mathrm{~min}$, followed by immersion in a solution of concentrated $\mathrm{HCl}$, DI water, and $\mathrm{H}_{2} \mathrm{O}_{2}(30 \% \mathrm{v} / \mathrm{v})(1: 5: 1)$ at $70{ }^{\circ} \mathrm{C}$ for $15 \mathrm{~min}$. Subsequently, it was rinsed with copious amounts of DI water and dried in a stream of Ar gas.

Chemical Modification of Wafers and Michael Lactonization. Formation of the Br Terminated SAM. Freshly cleaned silicon wafers were placed in a vial containing a freshly prepared $1 \mathrm{mM}$ solution of 11-bromoundecyltrichlorosilane in toluene for $16 \mathrm{~h}$. Once deposition was complete, the wafer was removed and rinsed with toluene and subsequently sonicated in toluene, $\mathrm{CH}_{2} \mathrm{Cl}_{2}$, and $\mathrm{CHCl}_{3}$ for 5 min each. The bromine terminated wafers were dried under a stream of Ar.

Conversion to Azide Terminated Layer. The bromine terminated wafer was immersed in a saturated solution of sodium azide in DMF $(10 \mathrm{~mL})$, and the reaction was stirred for $24 \mathrm{~h}$. Upon completion the azide terminated wafer was removed and rinsed with DMF. The wafer was sonicated in $\mathrm{EtOH}$ and $\mathrm{H}_{2} \mathrm{O}$ for 5 min each and dried under a stream of Ar.

Click Reaction To Form a Trifluoromethylenone Terminated Layer. To a round-bottomed flask containing EtOH $(8 \mathrm{~mL})$ was added the appropriate enone (1 equiv). $\mathrm{CuSO}_{4} \cdot 5 \mathrm{H}_{2} \mathrm{O}(10 \mathrm{~mol} \%)$ in $1 \mathrm{~mL}$ of $\mathrm{H}_{2} \mathrm{O}$ and sodium ascorbate $(15 \mathrm{~mol} \%)$ in $1 \mathrm{~mL}$ of $\mathrm{H}_{2} \mathrm{O}$ were then added. The azide terminated wafer was immersed in the reaction mixture for $24 \mathrm{~h}$. Upon completion, the enone terminated wafer was removed and rinsed with EtOH. The wafer was sonicated in $\mathrm{EtOH}$ and $\mathrm{H}_{2} \mathrm{O}$ for 5 min each and dried under a stream of Ar.

General Procedure A: Surface Michael Addition-Lactonization with $D H P B$. To a round-bottomed flask containing a stirrer bar and a solution of acid (1 equiv) in $\mathrm{CH}_{2} \mathrm{Cl}_{2}(3 \mathrm{~mL})$ was added DIPEA (1.5 equiv) and pivaloyl chloride ( 1.5 equiv) at $0{ }^{\circ} \mathrm{C}$ (see Supporting Information for details). The reaction mixture was allowed to stir at 0 ${ }^{\circ} \mathrm{C}$ for $20 \mathrm{~min}$. DHPB (5 mol \%), the Michael acceptor terminated silica wafer, and DIPEA ( 2.5 equiv) were added at $\mathrm{rt}$ and allowed to react for $24 \mathrm{~h}$. Upon completion, the lactone terminated wafer shard was removed and rinsed with $\mathrm{CH}_{2} \mathrm{Cl}_{2}$ and sonicated in $\mathrm{CH}_{2} \mathrm{Cl}_{2}$ and $\mathrm{CHCl}_{3}$ for $5 \mathrm{~min}$ each. The lactone terminated wafers were dried under a stream of Ar.

Characterization and Instrumentation. Each surface was characterized by its water contact angle (CA) to determine the wettability and hence obtain information about the surface termination. Atomic force microscopy (AFM) was employed to determine the cleanliness and roughness, X-ray photoelectron spectroscopy (XPS) to determine the chemical composition, and variable angle spectroscopic ellipsometry (VASE) to determine film thickness. Details are given below:

Contact Angle Measurements. Static contact angles were measured with Millipore filtered DI water using a G10 contact angle goniometer (Krüss $\mathrm{GmbH}$, Hamburg, Germany) in ambient conditions. Droplets of $\sim 3 \mu \mathrm{L}$ were dispensed from a microburet. Contact angle values reported below were taken from an average of at least two samples, each sample's contact angle being the average of the contact angle measured on each side of three droplets.

Atomic Force Microscopy. For AFM analysis a Bruker Dimension Icon system was employed in PeakForce Tapping mode using Vshaped cantilevers (Veeco SNL-A) of nominal spring constant $0.58 \mathrm{~N} /$ $\mathrm{m}$ and a nominal tip radius of $2 \mathrm{~nm}$. The peak force set point was $1-4$ $\mathrm{nN}$, and the scan rate was $1 \mathrm{~Hz}$. The RMS roughness of each surface 

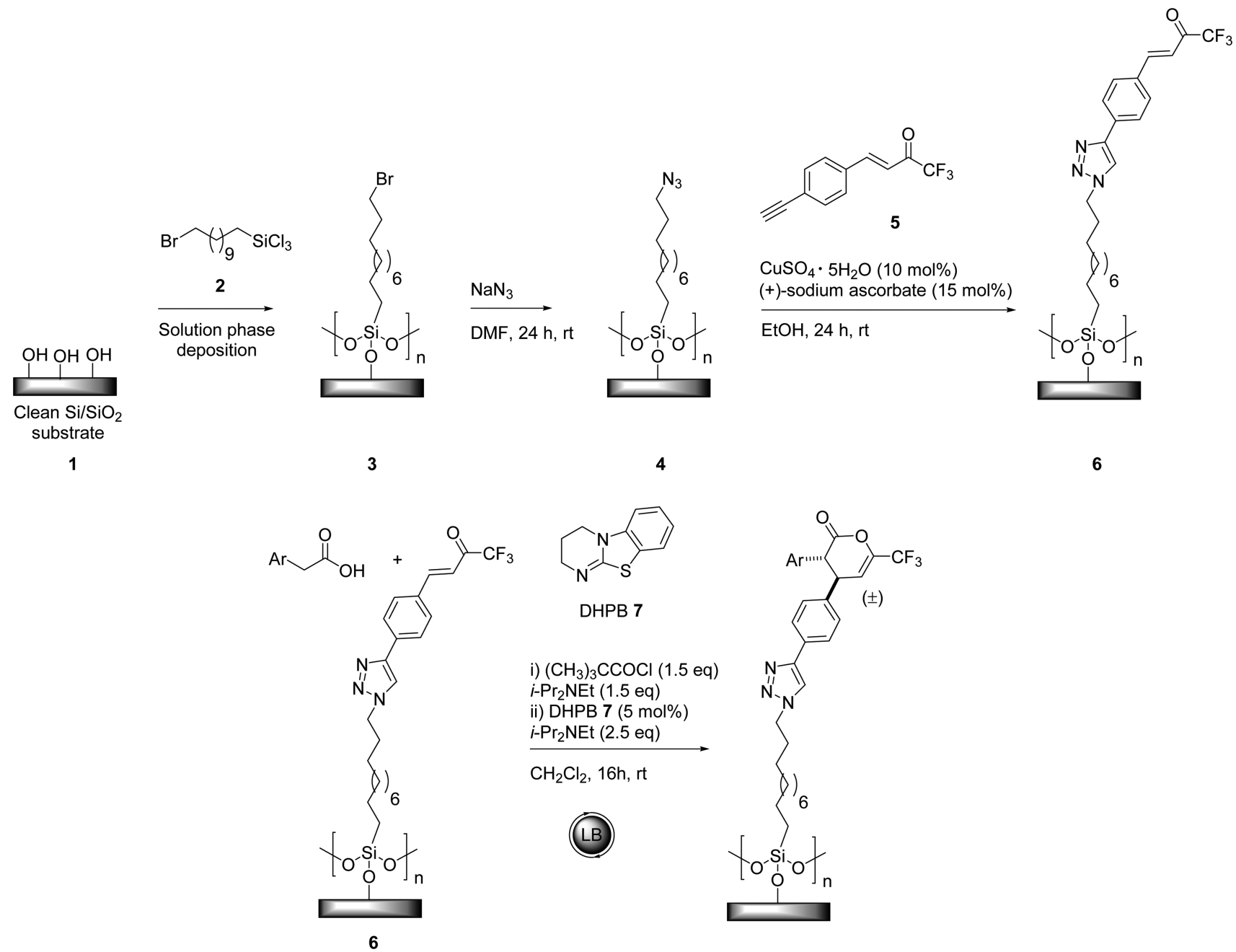

Figure 2. Summary of the modification process.

was characterized from $1 \times 1 \mu \mathrm{m}^{2}$ images of $512 \times 512$ pixels after appropriate image leveling. Quoted roughness values were calculated from an average of at least two samples and three images of each sample.

Ellipsometry. The thickness of the SAMs was measured with an M2000DI spectroscopic ellipsometer (J.A. Woollam Co., Inc., USA). Film thicknesses were extracted from fits to data collected at angles of incidence of $45^{\circ}-75^{\circ}$ in steps of $5^{\circ}$ over wavelengths of $600-1600$ $\mathrm{nm}$. The sample was modeled as a $1 \mathrm{~mm}$ thick Si substrate with an oxide layer of $1.7 \mathrm{~nm}$ atop which a Cauchy layer was used to represent the SAM. The thickness of the Cauchy layer was calculated using a value of 1.45 for the refractive index of the SAM at $\sim 1000 \mathrm{~nm}^{38,39}$ The quoted thickness values were calculated from an average of at least two samples with data collected from two areas of each sample.

$X$-ray Photoelectron Spectroscopy. XPS spectra were obtained using a Scienta 300 XPS instrument and $\mathrm{Al} \mathrm{K} \alpha$ radiation. The base pressure in the test chamber was around $1 \times 10^{-8} \mathrm{mbar}$. The detector had a takeoff angle of $90^{\circ}$ relative to the surface. Survey spectra and single region scans were recorded with the analyzer pass energy set to $150 \mathrm{eV}$. Some XPS spectra were also obtained using a K-Alpha instrument (Thermo Scientific) and $\mathrm{Al} \mathrm{K} \alpha$ radiation (NEXUS, Newcastle). During the analysis, the pressure in the instrument chamber was kept around $3 \times 10^{-8} \mathrm{mbar}$. The detector had a takeoff angle of $90^{\circ}$ relative to the surface. Survey spectra were recorded with the analyzer pass energy set to $200 \mathrm{eV}$. Single region scans were recorded with the pass energy of the analyzer set to $20 \mathrm{eV}$.

The XPS spectra were corrected for charging by shifting the aliphatic $\mathrm{C} 1 \mathrm{~s}$ peak to $284.6 \mathrm{eV}$. Elemental compositions of the various surfaces were determined using CasaXPS (Casa Software Ltd., UK) from the area under individual elemental peaks using sensitivity factors provided with the software as well as taking the transmission function of the analyzer into account. A Shirley background was subtracted, and the spectra were fitted using Gaussian-Lorentzian (30\% Gaussian, $70 \%$ Lorentzian) peak shapes.

\section{RESULTS}

Formation of $\mathrm{CF}_{3}$ Enone Terminated Surface 6. The trifluoromethylenone terminated surface $\mathbf{6}$ was formed in three steps from hydroxyl terminated wafer 1 (Figure 2). All samples were free of contaminants by optical inspection. Physical characteristics of each of the surfaces (clean silica 1 , bromine 3 , azide 4, and enone 6 terminated samples) are summarized in Table 1 from an average of at least two samples of each type and described in more detail in the following section.

Clean $\mathrm{Si} / \mathrm{SiO}_{2}$ Wafer 1 . The cleaned silica substrates 1 displayed very low water contact angle values $\left(\sim 5^{\circ}-20^{\circ}\right)$ as expected. The surfaces were smooth and free from contaminants. Using ellipsometry, a thickness for the silicon oxide layer of $1.70 \pm 0.10 \mathrm{~nm}$ was determined and was used in the analysis of ellipsometry data for subsequent surfaces.

Bromine Terminated SAM 3. A contact angle of around $83^{\circ}$ was a clear indication of the formation of a well-ordered bromine terminated monolayer 3 on the silica substrate. ${ }^{23,40}$ AFM showed a slight increase of surface roughness over the 
Table 1. Summary of the Film Parameters after Each Reaction Step

\begin{tabular}{|c|c|c|c|c|}
\hline sample type & CA (deg) & $\begin{array}{l}\text { thickness } \\
\text { (nm) }\end{array}$ & roughness $(\mathrm{nm})$ & $\begin{array}{c}\text { conv } \\
(\%)\end{array}$ \\
\hline clean $\mathrm{Si} / \mathrm{SiO}_{2} \mathbf{1}$ & $\approx 5-20$ & $\begin{array}{l}1.70 \pm 0.10 \\
\quad \text { (oxide) }\end{array}$ & $0.090 \pm 0.010$ & \\
\hline bromine $(\mathrm{Br}) 3$ & $82.9 \pm 0.8$ & $1.90 \pm 0.25$ & $0.100 \pm 0.020$ & \\
\hline azide $\left(\mathrm{N}_{3}\right) 4$ & $79.1 \pm 1.0$ & $1.76 \pm 0.22$ & $0.110 \pm 0.020$ & $\approx 80$ \\
\hline enone 6 & $72.6 \pm 2.5$ & $2.64 \pm 0.23$ & $0.160 \pm 0.040$ & $\approx 89$ \\
\hline
\end{tabular}

${ }^{a}$ Average values from at least two samples of each type are shown; thicknesses quoted are for that of the oxide layer for silica and total thickness of the organic layer thereafter.

clean $\mathrm{Si} / \mathrm{SiO}_{2}(0.090$ to $\sim 0.100 \mathrm{~nm})$ while a thickness of 1.90 $\mathrm{nm}$ is consistent with monolayer coverage.

Azide Terminated Surface 4. A decrease of the water contact angle by around $3^{\circ}$ was measured as a result of the surface modification with sodium azide. A slight but not statistically significant decrease in the thickness of the organic layer was measured by ellipsometry. The surface roughness increased by a small amount. XPS survey spectra indicated a lack of $\mathrm{Br}$ and an introduction of nitrogen as a result of the reaction. High-resolution XPS was used to quantify the proportion of the molecules converted from bromine to azide termination by comparison of the areas of the $\mathrm{Br} 3 \mathrm{~d}_{3 / 2}$ and $\mathrm{N}$ $1 \mathrm{~s}$ peak areas. Conversions of around $80 \%$ were routinely obtained. The $\mathrm{N} 1 \mathrm{~s}$ region of azide samples consists of three peaks of equal area corresponding to the three nitrogen atoms in different chemical environments. Peaks were fitted under the restriction of equal width and area with binding energies 3.3 and $3.9 \mathrm{eV}$ lower than the peak with the highest binding energy. ${ }^{41,42}$

Conversion to Trifluoromethylenone Surface 6. Trifluoromethylenone 5 was attached to the surface via a click reaction with the azide functional groups. Clear changes in the contact angle, thickness, and surface roughness accompanied this step. Appropriate postreaction cleaning ensured a clean surface (AFM image shown in Supporting Information as Figure S1). XPS survey spectra confirmed the presence of fluorine on the surface after the reaction (see Figure S2), while AFM showed minimal unbound material which suggests the click reaction was successful. The $\mathrm{N} 1 \mathrm{~s}$ region of the XPS of these samples sometimes included signals from nitrogen atoms characteristic of the 1,2,3-triazole only (Figure 3a), but often peaks from nitrogen atoms in residual azide groups were also observed (Figure $3 \mathrm{~b}$ ). The $\mathrm{N}$ 1s signal from the 1,2,3-triazole group was composed of three peaks relating to nitrogen atoms in three different chemical environments fitted under the restriction of equal area and width with binding energies 1.3 and $2.0 \mathrm{eV}$ lower than the peak with the highest binding energy. ${ }^{41,42}$ For spectra with residual azide groups, identifiable by a small peak at $\sim 404.5 \mathrm{eV}$, the same fitting procedure as in the case of the pure azide surface 4 was applied.

By comparing the area of $\mathrm{N}$ 1s peaks associated with the triazole to the total $\mathrm{N}$ 1s signal (consisting of triazole and remaining azide groups), the conversion of the click reaction was determined. Some samples showed quantitative conversion (Figure 3a), while the average conversion of the click reaction across all samples was calculated to be around $89 \%$.

High-resolution XPS data were collected for the $\mathrm{C}$ 1s region (see Figure 4), which confirms the attachment of the

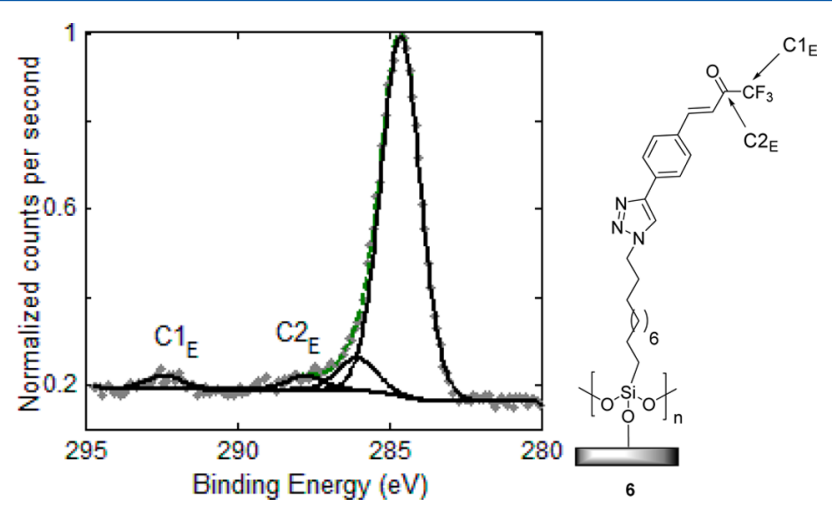

Figure 4. XPS data showing the $\mathrm{C} 1 \mathrm{~s}$ region of a typical $\mathrm{CF}_{3}$ enone sample 6.

trifluoromethylenone group through the appearance of peaks of equal area at around $292.5 \mathrm{eV}$ (marked $\mathrm{C1}_{\mathrm{E}}$ ) and $288.3 \mathrm{eV}$ (marked $\mathrm{C} 2_{\mathrm{E}}$ ) relating to the carbon atom of the $\mathrm{CF}_{3}$ group and that of the carbonyl, respectively. A shoulder to the aliphatic peak is also fitted at around $286.1 \mathrm{eV}$ corresponding to carbon atoms that are near neighbors of nitrogen atoms and the trifluoromethylenone group.

Formation of Dihydropyranones on the Surface. A summary of the data recorded for the substituted dihydropyranone samples is shown in Table 2. Each value is an average calculated from at least two examples of each dihydropyranone species.

The generality of the Michael lactonization process was investigated through variation of the arylacetic acid component.
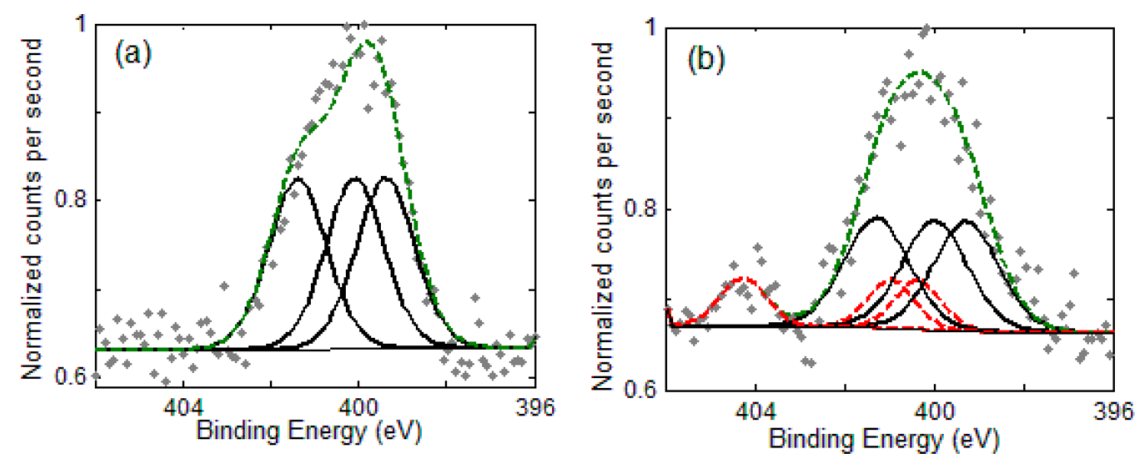

Figure 3. N 1s region of two enone samples 6. The spectrum in (a) shows peaks relating to triazole groups only, which suggests quantitative conversion for the click reaction. The spectrum in (b) consists of components from nitrogen atoms in both triazole (three large peaks, solid lines) and azide (three small peaks, dashed lines) environments, their relative areas giving a conversion of $\sim 84 \%$ for this sample. 
Table 2. Summary of Film Properties for Different Dihydropyranone Species ${ }^{a}$

\begin{tabular}{lcccc}
\multicolumn{1}{c}{ sample } & $\mathrm{CA}(\mathrm{deg})$ & $\begin{array}{c}\text { thickness } \\
(\mathrm{nm})\end{array}$ & roughness $(\mathrm{nm})$ & $\begin{array}{c}\text { conv } \\
(\%)\end{array}$ \\
4- $\mathrm{BrC}_{6} \mathrm{H}_{4} 8$ & $68.6 \pm 1.0$ & $3.10 \pm 0.28$ & $0.162 \pm 0.027$ & $\approx 51$ \\
4- $\mathrm{FC}_{6} \mathrm{H}_{4} 9$ & $71.3 \pm 1.1$ & $3.60 \pm 0.12$ & $0.178 \pm 0.054$ & $\approx 41$ \\
3-thiophene 10 & $69.8 \pm 2.4$ & $3.87 \pm 0.16$ & $0.247 \pm 0.045$ & $\approx 54$ \\
4- $\mathrm{NMe}_{2} \mathrm{C}_{6} \mathrm{H}_{4} \mathbf{1 1}$ & $70.0 \pm 2.2$ & $3.89 \pm 0.15$ & $0.155 \pm 0.055$ & $\approx 70$ \\
4- $\mathrm{CF}_{3} \mathrm{C}_{6} \mathrm{H}_{4} \mathbf{1 2}$ & $72.8 \pm 1.5$ & $3.76 \pm 0.24$ & $0.180 \pm 0.050$ & $\approx 42$
\end{tabular}

${ }^{a}$ The conversion percentages were calculated from the relative areas of XPS C 1s peaks marked $\left(\mathrm{C} 2_{\mathrm{E}}+\mathrm{C} 2_{\mathrm{L}}\right)$ and $\mathrm{C} 3_{\mathrm{L}}$ as described in the text.

Using the standard conditions (outlined in General Procedure A), the reaction readily tolerates heteroaryl (3-thiophenyl) as well as 4-aryl substitution, including electron-donating (4$\mathrm{NMe}_{2}$ ) and electron-withdrawing $\left(4-\mathrm{CF}_{3}\right)$ substituents (Figure $5)$.<smiles>CC(C)(C)C(F)(F)C1=CC(c2ccc(Br)cc2)[C@H](c2ccc(Br)cc2)C(=O)O1</smiles>

$( \pm)$<smiles>[Y6]c1ccc([C@H]2C=C(C(F)(F)F)OC(=O)[C@H]2c2ccc(F)cc2)cc1</smiles>

$( \pm)$<smiles>CC(C)(F)C1=CC(c2ccc(C(F)(F)F)cc2)[C@H](c2ccsc2)C(=O)O1</smiles>

$( \pm)$
$9(41 \%)$
$10(54 \%)$<smiles>CN(C)c1ccc([C@H]2C(=O)OC(C(F)(F)F)=CC2c2ccc(C(F)(F)F)cc2)cc1</smiles>

$( \pm)$<smiles>CC(C)(F)c1ccc(C2C=C(C(F)(F)F)OC(=O)C2c2ccc(C(F)(F)F)cc2)cc1</smiles>

$( \pm)$

Figure 5. Variation of the arylacetic acid component in the reaction.

Formation of dihydropyranone terminated samples was generally accompanied by a small drop in contact angle compared to that of the enone samples. The Michael additionlactonization step increased the thickness of the organic layer by around $0.5-1.3 \mathrm{~nm}$ in comparison to the enone samples to a

total value of around 3.1-3.9 $\mathrm{nm}$. The roughness of the dihydropyranone films was greater than for the enone samples, as a result of the additional reaction step. The surface cleanliness was also reduced as could be identified by AFM (see Figure S3) and by comparing the roughness of the dihydropyranone surfaces 8-12 with that of the enone 6 .

Formation of the dihydropyranone was confirmed by the appearance of a peak at $\sim 289.6 \mathrm{eV}$ in the C 1s XPS spectra corresponding to carbonyl species (Figure 6), along with the appearance of "marker" atoms in the survey and high-resolution spectra. For example, the formation of the thiophenesubstituted dihydropyranone $\mathbf{1 0}$ was confirmed by the appearance of a peak relating to the sulfur atom in the thiophene (inset to Figure 6). In addition to a peak for aliphatic carbon atoms, four peaks were identified in the $\mathrm{C} 1 \mathrm{~s}$ region which were found to be at around $292.5 \mathrm{eV}$ (labeled $\mathrm{C} 1_{\mathrm{E}}+$ $\mathrm{C} 1_{\mathrm{L}}$ ), $289.7 \mathrm{eV}$ (labeled $\mathrm{C} 3_{\mathrm{L}}$ ), $288.3 \mathrm{eV}$ (labeled $\mathrm{C} 2_{\mathrm{E}}+\mathrm{C} 2_{\mathrm{L}}$ ), and $286.0 \mathrm{eV}$ and account for carbon atoms in different chemical environments. The peaks at 292.5 and $288.3 \mathrm{eV}$ were fitted with the constraint of having equal areas as both have their origin in the formation of the enone species 6. These peaks contain carbon atoms in unreacted enone species (atoms marked $\mathrm{C1}_{\mathrm{E}}$ and $\mathrm{C} 2_{\mathrm{E}}$ ) and strands successfully converted to lactone species (atoms marked $\mathrm{C}_{\mathrm{L}}$ and $\mathrm{C} 2_{\mathrm{L}}$ ). A smaller peak labeled $\mathrm{C} 3_{\mathrm{L}}$ appears at around $289.6 \mathrm{eV}$ due to the formation of the dihydropyranone. The final shifted peak at around $286.0 \mathrm{eV}$ accounts for carbon atoms in electronegative environments adjacent to the nitrogen atoms, near neighbors of carbons $\mathrm{Cl}_{\mathrm{E}}$, $\mathrm{Cl}_{\mathrm{L}}$, and $\mathrm{C} 3_{\mathrm{L}}$, and bonded to some of the lactone "marker" atoms, for example, the carbon atom to which the $\mathrm{F}$ atom is bonded in the related lactone 9 .

Furthermore, Figure 7 shows the C 1s region for trifluoromethyl-substituted dihydropyranone 12 . The area of the peak at $292.5 \mathrm{eV}$ is increased over that of the enone terminated surface 6 by the Michael lactonization step as can clearly be seen in the spectra. The area of the peak labeled $\left(\mathrm{Cl}_{\mathrm{E}}\right.$ $\left.+\mathrm{Cl}_{\mathrm{L}}+\mathrm{C} 4_{\mathrm{L}}\right)$ is equal to the sum of the areas labeled $\left(\mathrm{C} 2_{\mathrm{E}}+\right.$ $\mathrm{C} 2_{\mathrm{L}}$ ) and $\mathrm{C} 3_{\mathrm{L}}$, confirming the success of the Michael lactonization step.

C 1 s regions fitted in this way gave consistent results across all lactone samples. The conversion, $c$, from enone 6 to dihydropyranone via Michael lactonization was calculated from the relative area of peaks labeled $\left(\mathrm{C} 2_{\mathrm{E}}+\mathrm{C} 2_{\mathrm{L}}\right)$ and $\mathrm{C} 3_{\mathrm{L}}$ in
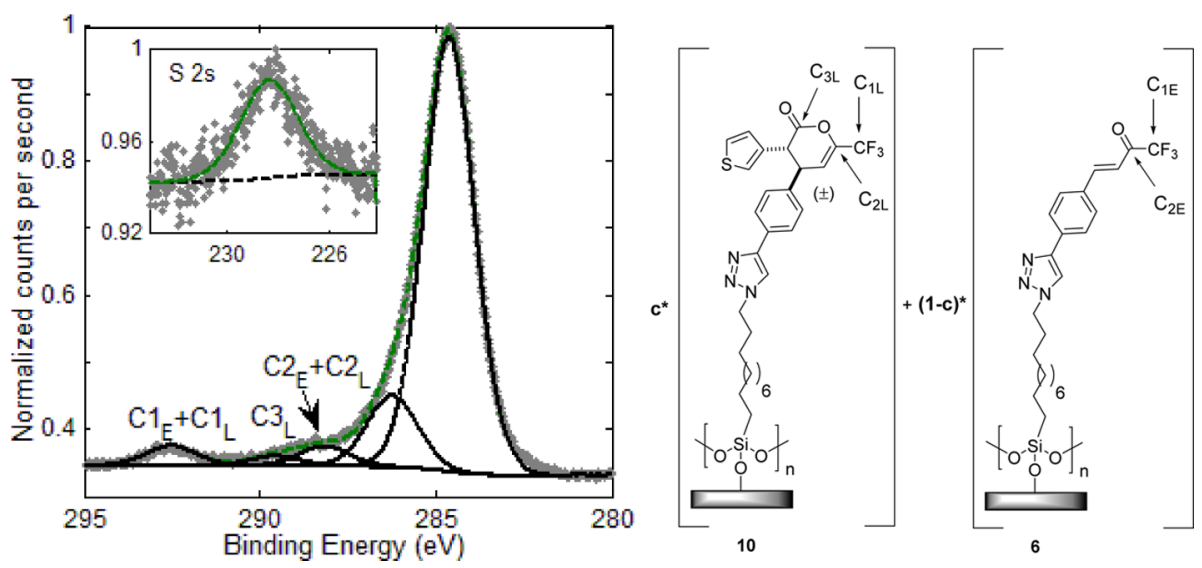

Figure 6. C 1s region of the XPS spectrum of a thiophene-substituted dihydropyranone sample 10. The data may consist of peaks from both enone 6 and dihydropyranone 10 terminated strands with their relative population described by the conversion. The inset shows the $S 2 s$ region of the same sample, confirming the presence of sulfur on the surface. 

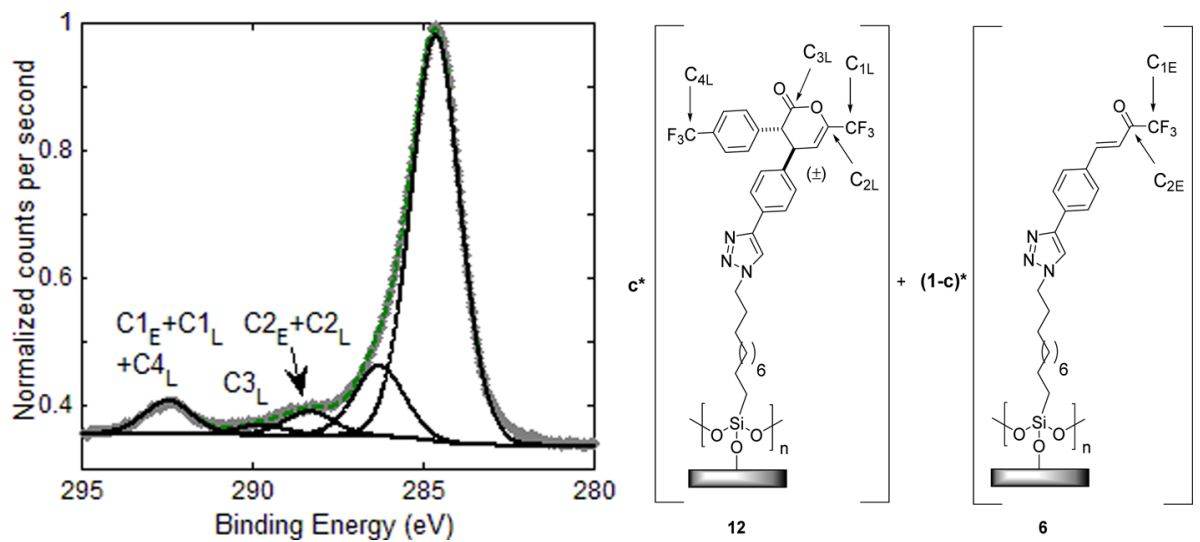

Figure 7. C 1s region of the XPS spectrum of a trifluoromethyl lactone sample 12. The data may consist of peaks from both enone 6 and lactone 12 terminated strands with their relative population described by the conversion.

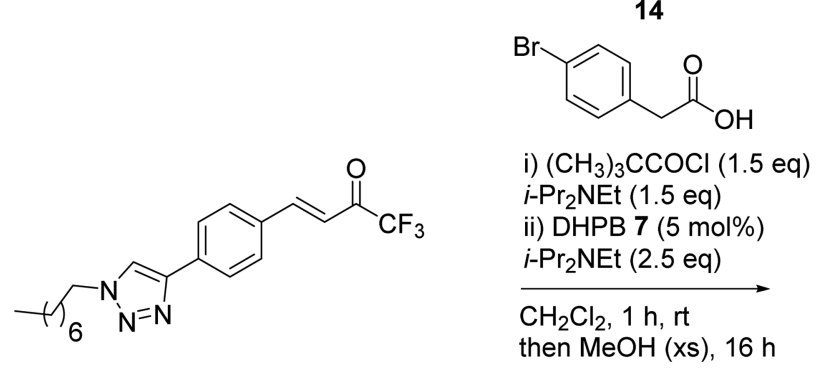

13

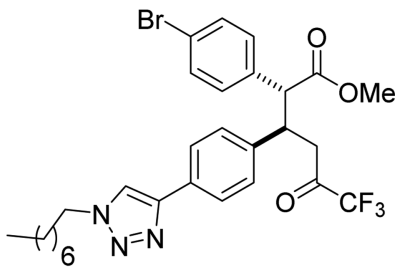

$( \pm)-15$

dr 80:20 (anti:syn)

Figure 8. Solution phase model of diastereoselectivity.

Figure 6 via the relation $c=\operatorname{Area}\left(C 3_{\mathrm{L}}\right) / \operatorname{Area}\left(\mathrm{C} 2_{\mathrm{E}}+\mathrm{C} 2_{\mathrm{L}}\right)$. The resulting conversion was between 40 and $70 \%$ across all samples (see Table 2). No unidentified sulfur or nitrogen was present in the XPS spectra, confirming that the catalyst 7 was successfully removed from the surface during the reaction and/ or by the postdeposition cleaning procedure. To further probe the catalytic necessity of the isothiourea for surface functionalization, a control reaction was performed where a trifluoromethylenone sample 6 was exposed to the Michael addition-lactonization conditions with the omission of the catalyst DHPB 7. Formation of a dihydropyranone was not observed and the surface had properties equivalent to that of other trifluoromethylenone surfaces.

Model Study in Solution. While XPS allows the reaction conversion to be estimated, none of the methods of characterization allow the diastereoselectivity of the organocatalytic process on the surface to be evaluated. To estimate the level of diastereocontrol that may be expected in this process, a model system was devised whereby a system analogous to that assumed on the $\mathrm{Si} / \mathrm{SiO}_{2}$ surface was subjected to the same reaction conditions in solution. A solution analogue of the surface tethered trifluoromethylenone (see Figure S4) was designed to undergo an analogous Michael addition-lactonization (Figure 8). The diastereoselectivity of the solution Michael lactonization reaction was measured by ${ }^{1} \mathrm{H}$ NMR spectroscopy, a dr of 80:20 obtained (see Supporting Information for details). This level of relative stereocontrol, combined with the ${ }^{1} \mathrm{H}-{ }^{1} \mathrm{H}$ coupling constants of $J 10.9$ and $3.8 \mathrm{~Hz}$ for the major diastereoisomer, is consistent with the expected "anti"-stereocontrol observed in previous solution based studies.

\section{DISCUSSION}

Formation of the Trifluoromethylenone Surface. Formation of a well-ordered bromine terminated SAM 3 is important for the success of the modification of the surface. The contact angles for the bromine 3 and azide 4 SAMs are in agreement with those observed previously. ${ }^{5,23,40}$ The thicknesses of the bromine 3 and azide 4 terminated films were marginally higher (by $\sim 0.3$ and $\sim 0.2 \mathrm{~nm}$, respectively) compared to previous reported values. ${ }^{43}$ A small decrease in thickness as a result of the bromine to azide conversion was indicated by ellipsometry but was well within experimental error. A thickness increase of $\sim 0.14 \mathrm{~nm}$ has previously been reported for this reaction. ${ }^{43}$ The relatively large thickness for the bromide film 3 reported here could be a result of this surface having a high affinity for the adsorption of atmospheric contaminants. Average conversion rates of around $80 \%$ were observed for the bromine to azide reaction, which is to the lower end of the conversions previously published for this reaction on a surface. ${ }^{5}$ Along with the greater thickness for our monolayers this might imply that our bromine terminated SAM 3 was slightly contaminated. A more densely packed film than some of those previous reported in the literature could also result in a slightly lower conversion rate if the access to the remaining $\mathrm{Br}$ groups becomes difficult due to steric constraints.

Formation of the trifluoromethylenone 6 was accompanied by a clear peak in the C 1s XPS spectra at $\sim 292.5 \mathrm{eV}$ (Figure $4)$, relating to a $-\mathrm{CF}_{3}$ group. ${ }^{8} \mathrm{AFM}$ measurements showed a reasonably clean surface. Along with an increase of thickness of the organic layer this implies that the click reaction was 
successful and the trifluoromethylenone was covalently bound. High-resolution XPS spectra of the N 1s region was used as further confirmation of the click reaction. Peaks relating to nitrogen atoms in unreacted azide moieties were clearly distinguishable from those relating to the triazole structures. A conversion of around $89 \%$ was typically calculated for the reaction. Some samples showed higher conversions when the azide peak was indistinguishable from the noise background in the N 1s XPS spectra. The samples with higher conversions in the click reaction are possibly linked to samples whose initial $\mathrm{Br}$ SAM 3 was slightly less densely packed, thus allowing better access.

Formation of Dihydropyranone Surface. The functionalization of a $\mathrm{Si} / \mathrm{SiO}_{2}$ surface 1 through Michael lactonization was explored as a potential route to the incorporation of the dihydropyranone structure to the surface. This reaction process was chosen because of its generality, scope and ease of operation, and the possible diversity of functionalization by changing the arylacetic acid component of the reaction. Five different arylacetic acids (Figure 5) were selected from the previously reported study ${ }^{33}$ and tested in the Michael addition-lactonization process on the surface. Each had "marker" atoms such that formation of the lactone was clearly identifiable in XPS survey spectra.

A variation in water contact angle values was observed (Table 2) for different substituted dihydropyranone terminations, indicating that the araylacetic acid component was exposed to the surface of the sample. As might be expected, the trifluoromethyl-substituted dihydropyranone $\mathbf{1 2}$ had the largest contact angle of the lactones due to the nature of the $\mathrm{CF}_{3}$ group. The contact angle of the para- $\mathrm{CF}_{3}$-substituted dihydropyranone 12 was not very much different than that of the trifluoromethylenone terminated precursor surface $\mathbf{6}$ as similar groups were likely exposed during contact angle measurements: both terminations possess hydrophobic $\left(-\mathrm{CF}_{3}\right)$ and hydrophilic $(\mathrm{C}=\mathrm{O})$ components. The roughness of the dihydropyranone films was greater than for the enone terminated samples as a result of the additional reaction step and can be understood in the context of the $40-70 \%$ conversion of enone surface $\mathbf{6}$ to substituted dihydropyranone terminated surface. The thiophene-substituted dihydropyranone 10 showed the highest surface roughness and a reasonably low contact angle relative to other dihydropyranone samples which could indicate degradation. However, no evidence of this could be seen in XPS spectra or thickness of the organic layer.

The Michael lactonization increased the average thickness of the organic layers by $0.5-1.3 \mathrm{~nm}$, a reasonably large amount considering the size of the additional structure. In the fitting of ellipsometry data $n=1.45$ was used for the organic layer. ${ }^{38,39}$ Refractive indices of $n \sim 1.55$ are sometimes measured for aromatics on surfaces. ${ }^{44}$ If $n>1.45$ were used, it would have the result of decreasing the fitted film thickness. For example, if a value of $n=1.55$ is used for the trifluoromethyl dihydropyranone surface 12 , the measured thickness of the organic layer drops from 3.76 to $3.08 \mathrm{~nm}$. However, the whole organic layer does not consist of aromatic rings, and hence a refractive index between 1.45 and 1.55 may be the most appropriate. Unfortunately, the true refractive index and layer thickness cannot be determined simultaneously due to strong parameter coupling in fits to ellipsometry data for very thin films such as those studied here.

XPS is an invaluable tool for use in the confirmation of the success of each modification step. The arylacetic acids employed in this study were chosen with their "marker" atoms in mind. For the thiophene-substituted dihydropyranone 10 the appearance of sulfur in the XPS survey spectra confirmed that the thiophene moiety was present on the surface. Likewise, the appearance of $\mathrm{Br}$, and excess $\mathrm{F}$ and $\mathrm{N}$ confirmed the presence of the related dihydropyranones on the sample surfaces. The conversion to and formation of the lactone ring was confirmed by the appearance of the peak labeled $\mathrm{C} 3_{\mathrm{L}}$ in the $\mathrm{C} 1 \mathrm{~s}$ high-resolution XPS data (Figure 6). The validity of this assignment is most clear in the spectra for the trifluoromethyldihydropyranone $\mathbf{1 2}$ where the peak labeled $\left(\mathrm{C1}_{\mathrm{E}}+\mathrm{C1}_{\mathrm{L}}+\mathrm{C} 4_{\mathrm{L}}\right)$ due to the $\mathrm{CF}_{3}$ groups is inflated relative to the peak labeled $\left(\mathrm{C} 2_{\mathrm{E}}+\mathrm{C} 2_{\mathrm{L}}\right)$ by an area equivalent to that of peak $\mathrm{C} 3_{\mathrm{L}}$. The chemical environments of carbons marked $\mathrm{C} 1_{\mathrm{L}}$ and $\mathrm{C}_{\mathrm{L}}$ in the dihydropyranone structures should be very similar to those marked $C 1_{E}$ and $C 2_{E}$, respectively, of the enone terminated surface 6 . If the peak assignment in the $C 1$ s regions for both enone and dihydropyranone species is correct, then peaks marked $\mathrm{C} 1_{\mathrm{E}}, \mathrm{C} 1_{\mathrm{L}}$ and $\mathrm{C} 2_{\mathrm{E}}, \mathrm{C} 2_{\mathrm{L}}$ should appear at equivalent binding energies with little deviation between individual data sets. Across all enone and dihydropyranone samples peaks $\mathrm{C1}_{\mathrm{E}}$ and $\left(\mathrm{Cl}_{\mathrm{E}}+\mathrm{C1}_{\mathrm{L}}\right)$ appear at $292.5 \pm 0.1 \mathrm{eV}$. Peaks $C 2_{\mathrm{E}}$ and $\left(\mathrm{C} 2_{\mathrm{E}}+\mathrm{C} 2_{\mathrm{L}}\right)$ appear at $288.3 \pm 0.2 \mathrm{eV}$ over all enone and dihydropyranone terminated samples. Likewise, the position of the peak $\mathrm{C}_{\mathrm{L}}$ for dihydropyranone samples was consistently fitted at a binding energy of $289.6 \pm 0.4 \mathrm{eV}$ under the single constraint of equal peak widths for all $\mathrm{C} 1 \mathrm{~s}$ peak.

The conversion from enone 6 to dihydropyranone terminated surfaces was calculated to be $40-70 \%$ across all functionalizations. Assuming an average value of $50 \%$ for this step, the total conversion of the bromine SAM 3 to dihydropyranone terminated surfaces was around $36 \%$. However, the lactone structure will have a much larger "radius" than that of the bromine SAM 3 such that a large fraction of the surface area may be covered by lactone species. The density of $\mathrm{Si}-\mathrm{OH}$ groups on silica surfaces available for attachment of SAM molecules is between 4.5 and $5 \mathrm{~nm}^{-2} \cdot{ }^{10,45,46}$ If a density of $\mathrm{Si}-\mathrm{OH}$ groups on silica surface of 4.5 per $\mathrm{nm}^{2}$ is used and one bromine terminated precursor molecule 2 attaches to each available $\mathrm{Si}-\mathrm{OH}$, then the radius of the cylinder within which each strand in the monolayer exists is approximately $0.27 \mathrm{~nm}$. With a total conversion of bromine 3 to dihydropyranone terminated strands of $36 \%$ on average, a radius of approximately $0.44 \mathrm{~nm}$ is calculated for each lactone strand. This value does not appear to be huge given the bulky nature of the groups attached to the surface. Therefore, while the ultimate conversion of bromine terminated strands 3 to lactone species was reasonably low, the density of lactone species and their surface coverage are relatively high. Higher conversions for the Michael lactonization reaction might be observed if the overall film coverage was lower: i.e., if the initial $\mathrm{Br}$ terminated monolayer 3 were less densely packed, then there is likely to be greater space between adjacent SAM molecules, potentially allowing more accessibility for the arylacetic acid and catalyst 7 in the lactonization step. Finally, we note that the catalyst 7 used for the Michael lactonization contains sulfur and nitrogen atoms, but no excess $\mathrm{S}$ or $\mathrm{N}$ was observed in the XPS survey scans and high resolution spectra; thus, it appears that the catalyst was removed from the surface.

\section{CONCLUSIONS}

In this work five separate dihydropyranone species have been formed on a silicon oxide surface 1 through organocatalytic 
functionalization of arylacetic acids promoted by the achiral isothiourea DHPB 7. Each of the arylacetic acid components tested formed the lactone structure with a conversion rate of $40-70 \%$. As such, the route presented is an effective method to build a variety of complex surfaces containing this functionality. The consistency of this methodology suggests that a wide variety of phenylacetic acid derivatives would also work on the surface, suggesting this may be a flexible methodology for surface functionalization. Holmes et al. ${ }^{47}$ demonstrated that a Pd-mediated cross-coupling reaction can successfully take place on the surface using aryl bromides and a series of aryl boronic acids, which opens up the possibility of further functionalization on the surface.

While the achiral isothiourea catalyst DHPB 7 was used in this study, previous work in our laboratory has shown that chiral isothioureas can induce high diastereo- and enantiocontrol in a variety of Michael addition-lactonization processes in solution and this might present an opportunity for the in situ formation of chiral surfaces. This is currently under investigation in our laboratory.

\section{ASSOCIATED CONTENT}

\section{(5) Supporting Information}

Raw research data supporting this publication can be accessed at http://dx.doi.org/10.17630/295101cc-a906-459c-8c79b44a207cb5aa. The Supporting Information is available free of charge on the ACS Publications website at DOI: 10.1021/ acs.langmuir.5b04686.

\section{Further experimental details (PDF)}

\section{AUTHOR INFORMATION}

\section{Corresponding Authors}

*Fax +44 1334 463808; phone +44 1334 463896; e-mail ads10@st-andrews.ac.uk (A.D.S.).

*Fax +44 1334 463808; phone +44 1334 463889; e-mail gh23@st-andrews.ac.uk (G.H.).

\section{Author Contributions}

R.C. and J.D.P. contributed equally to this work.

\section{Notes}

The authors declare no competing financial interest.

\section{ACKNOWLEDGMENTS}

Financial support from the EPSRC (EP/K000411/1 and EP/ L017008/1) is gratefully acknowledged. We thank Dr. Steve Francis (St Andrews) for measuring several XPS spectra. X-ray photoelectron spectra were also obtained at the National EPSRC XPS Users' Service (NEXUS) Newcastle, UK, an EPSRC Mid-Range Facility.

\section{REFERENCES}

(1) Sagiv, J. Organized Monolayers by Adsorption. 1. Formation and Structure of Olephobic Mixed Monolayers on Solid Surfaces. J. Am. Chem. Soc. 1980, 102, 92-98.

(2) Ulman, A. Formation and structure of self-assembled monolayers. Chem. Rev. 1996, 96 (4), 1533-1554.

(3) Onclin, S.; Ravoo, B. J.; Reinhoudt, D. N. Engineering silicon oxide surfaces using self-assembled monolayers. Angew. Chem., Int. Ed. 2005, 44 (39), 6282-6304.

(4) Chechik, V.; Crooks, R. M.; Stirling, C. J. M. Reactions and reactivity in self-assembled monolayers. Adv. Mater. 2000, 12 (16), $1161-1171$
(5) Haensch, C.; Hoeppener, S.; Schubert, U. S. Chemical modification of self-assembled silane based monolayers by surface reactions. Chem. Soc. Rev. 2010, 39 (6), 2323-2334.

(6) Pujari, S. P.; Scheres, L.; Marcelis, A. T. M.; Zuilhof, H. Covalent Surface Modification of Oxide Surfaces. Angew. Chem., Int. Ed. 2014, 53 (25), 6322-6356.

(7) Adamkiewicz, M.; O’Hagan, D.; Hähner, G. Organic chemistry on surfaces: Direct cyclopropanation by dihalocarbene addition to vinyl terminated self-assembled monolayers (SAMs). Beilstein J. Org. Chem. 2014, 10, 2897-2902.

(8) Adamkiewicz, M.; O’Hagan, D.; Hähner, G. Bis(trifluoromethyl)methylene Addition to Vinyl-Terminated SAMs: A Gas-Phase C-C Bond-Forming Reaction on a Surface. Langmuir 2014, 30 (19), 54225428.

(9) Adamkiewicz, M.; O’Hara, T.; O’Hagan, D.; Hähner, G. A vapor phase deposition of self-assembled monolayers: Vinyl-terminated films of volatile silanes on silicon oxide substrates. Thin Solid Films 2012, 520 (22), 6719-6723.

(10) Wasserman, S. R; Tao, Y. T.; Whitesides, G. M. Structure and reactivity of alkylsiloxane monolayers formed by reaction of alkyltrichlorosilanes on silicon substrates. Langmuir 1989, 5 (4), 1074-1087.

(11) Peanasky, J.; Schneider, H. M.; Granick, S.; Kessel, C. R. SelfAssembled Monolayers on Mica for Experiments Utilizing the Surface Forces Apparatus. Langmuir 1995, 11 (3), 953-962.

(12) Su, X.-L.; Li, Y. A self-assembled monolayer-based piezoelectric immunosensor for rapid detection of Escherichia coli O157:H7. Biosens. Bioelectron. 2004, 19 (6), 563-574.

(13) Cheng, Y.-A.; Zheng, B.; Chuang, P.-h.; Hsieh, S. Solvent Effects on Molecular Packing and Tribological Properties of Octadecyltrichlorosilane Films on Silicon. Langmuir 2010, 26 (11), 8256-8261.

(14) Booth, B. D.; Vilt, S. G.; Lewis, J. B.; Rivera, J. L.; Buehler, E. A.; McCabe, C.; Jennings, G. K. Tribological Durability of Silane Monolayers on Silicon. Langmuir 2011, 27 (10), 5909-5917.

(15) Maoz, R; Cohen, H.; Sagiv, J. Specific Nonthermal Chemical Structural Transformation Induced by Microwaves in a Single Amphiphilic Bilayer Self-Assembled on Silicon. Langmuir 1998, 14 (21), 5988-5993.

(16) Maboudian, R.; Ashurst, W. R.; Carraro, C. Self-assembled monolayers as anti-stiction coatings for MEMS: characteristics and recent developments. Sens. Actuators, A 2000, 82 (1-3), 219-223.

(17) Arya, S. K.; Solanki, P. R.; Datta, M.; Malhotra, B. D. Recent advances in self-assembled monolayers based biomolecular electronic devices. Biosens. Bioelectron. 2009, 24 (9), 2810-2817.

(18) Vashist, S. K.; Lam, E.; Hrapovic, S.; Male, K. B.; Luong, J. H. T. Immobilization of Antibodies and Enzymes on 3-Aminopropyltriethoxysilane-Functionalized Bioanalytical Platforms for Biosensors and Diagnostics. Chem. Rev. 2014, 114 (21), 11083-11130.

(19) Kirsch, J.; Siltanen, C.; Zhou, Q.; Revzin, A.; Simonian, A. Biosensor technology: recent advances in threat agent detection and medicine. Chem. Soc. Rev. 2013, 42 (22), 8733-8768.

(20) Samanta, D.; Sarkar, A. Immobilization of bio-macromolecules on self-assembled monolayers: methods and sensor applications. Chem. Soc. Rev. 2011, 40 (5), 2567-2592.

(21) Beeby, S.; Ensell, G.; Kraft, N.; White, N. MEMS Mechanical Sensors; Artech House Publishers: London, 2004.

(22) Sullivan, T. P.; Huck, W. T. S. Reactions on monolayers: Organic synthesis in two dimensions. Eur. J. Org. Chem. 2003, 2003, $17-29$.

(23) Balachander, N.; Sukenik, C. N. Monolayer transformation by nucleophilic substitution: Applications to the creation of new monolayer assemblies. Langmuir 1990, 6 (11), 1621-1627.

(24) Wang, Y.; Cai, J.; Rauscher, H.; Behm, R. J.; Goedel, W. A. Maleimido-Terminated Self-Assembled Monolayers. Chem. - Eur. I. 2005, 11 (13), 3968-3978.

(25) Onclin, S.; Mulder, A.; Huskens, J.; Ravoo, B. J.; Reinhoudt, D. N. Molecular Printboards: Monolayers of $\beta$-Cyclodextrins on Silicon Oxide Surfaces. Langmuir 2004, 20 (13), 5460-5466. 
(26) Haensch, C.; Hoeppener, S.; Schubert, U. S. Chemical surface reactions by click chemistry: coumarin dye modification of 11bromoundecyltrichlorosilane monolayers. Nanotechnology 2008, 19 (3), 7.

(27) Pookpanratana, S.; Savchenko, I.; Natoli, S. N.; Cummings, S. P.; Richter, L. J.; Robertson, J. W. F.; Richter, C. A.; Ren, T.; Hacker, C. A. Attachment of a Diruthenium Compound to $\mathrm{Au}$ and $\mathrm{SiO}_{2} / \mathrm{Si}$ Surfaces by "Click" Chemistry. Langmuir 2014, 30 (34), 1028010289.

(28) Huisgen, R. 1,3-Dipolar Cycloadditions. Proc. Chem. Soc. 1961, No. October, 357-396.

(29) MacMillan, D. W. The advent and development of organocatalysis. Nature 2008, 455 (7211), 304-308.

(30) Dalko, P. I.; Moisan, L. In the Golden Age of Organocatalysis. Angew. Chem., Int. Ed. 2004, 43 (39), 5138-5175.

(31) Seayad, J.; List, B. Asymmetric organocatalysis. Org. Biomol. Chem. 2005, 3 (5), 719-724.

(32) Cortez, G. S.; Tennyson, R. L.; Romo, D. Intramolecular, Nucleophile-Catalyzed Aldol-Lactonization (NCAL) Reactions: Catalytic, Asymmetric Synthesis of Bicyclic $\beta$-Lactones. J. Am. Chem. Soc. 2001, 123 (32), 7945-7946.

(33) Morrill, L. C.; Douglas, J.; Lebl, T.; Slawin, A. M. Z.; Fox, D. J.; Smith, A. D. Isothiourea-mediated asymmetric Michael-lactonisation of trifluoromethylenones: a synthetic and mechanistic study. Chem. Sci. 2013, 4 (11), 4146-4155.

(34) Gruttadauria, M.; Giacalone, F.; Noto, R. Supported proline and proline-derivatives as recyclable organocatalysts. Chem. Soc. Rev. 2008, 37 (8), 1666-1688.

(35) Riente, P.; Yadav, J.; Pericàs, M. A. A Click Strategy for the Immobilization of MacMillan Organocatalysts onto Polymers and Magnetic Nanoparticles. Org. Lett. 2012, 14 (14), 3668-3671.

(36) Osorio-Planes, L.; Rodríguez-Escrich, C.; Pericàs, M. A. Enantioselective Continuous-Flow Production of 3-Indolylmethanamines Mediated by an Immobilized Phosphoric Acid Catalyst. Chem. - Eur. J. 2014, 20 (8), 2367-2372.

(37) Hafez, A. M.; Taggi, A. E.; Dudding, T.; Lectka, T. Asymmetric Catalysis on Sequentially-Linked Columns. J. Am. Chem. Soc. 2001, 123 (44), 10853-10859.

(38) Tillman, N.; Ulman, A.; Schildkraut, J. S.; Penner, T. L. Incorporation of Phenoxy Groups in Self-Assembled Monolayers of Trichlorosilane Derivatives - Effects on Film Thickness, Wettability, and Molecular-Orientation. J. Am. Chem. Soc. 1988, 110 (18), 61366144.

(39) Angst, D. L.; Simmons, G. W. Moisture Absorption Characteristics of Organosiloxane Self-Assembled Monolayers. Langmuir 1991, 7 (10), 2236-2242.

(40) Heise, A.; Stamm, M.; Rauscher, M.; Duschner, H.; Menzel, H. Mixed silane self assembled monolayers and their in situ modification. Thin Solid Films 1998, 327, 199-203.

(41) Darlatt, E.; Nefedov, A.; Traulsen, C. H. H.; Poppenberg, J.; Richter, S.; Dietrich, P. M.; Lippitz, A.; Illgen, R.; Kuhn, J.; Schalley, C. A.; Woll, C.; Unger, W. E. S. Interpretation of experimental N K NEXAFS of azide, 1,2,3-triazole and terpyridyl groups by DFT spectrum simulations. J. Electron Spectrosc. Relat. Phenom. 2012, 185 (12), 621-624.

(42) Heinrich, T.; Traulsen, C. H. H.; Darlatt, E.; Richter, S.; Poppenberg, J.; Traulsen, N. L.; Linder, I.; Lippitz, A.; Dietrich, P. M.; Dib, B.; Unger, W. E. S.; Schalley, C. A. The versatility of "click" reactions: molecular recognition at interfaces. RSC Adv. 2014, 4 (34), 17694-17702.

(43) Rozkiewicz, D. I.; Janczewski, D.; Verboom, W.; Ravoo, B. J.; Reinhoudt, D. N. "Click" chemistry by microcontact printing. Angew. Chem., Int. Ed. 2006, 45 (32), 5292-5296.

(44) Bruno, G.; Babudri, F.; Operamolla, A.; Bianco, G. V.; Losurdo, M.; Giangregorio, M. M.; Omar, O. H.; Mavelli, F.; Farinola, G. M.; Capezzuto, P.; Naso, F. Tailoring Density and Optical and Thermal Behavior of Gold Surfaces and Nanoparticles Exploiting Aromatic Dithiols. Langmuir 2010, 26 (11), 8430-8440.
(45) Zhuravlev, L. T. Concentration of Hydroxyl-Groups on the Surface of Amorphous Silicas. Langmuir 1987, 3 (3), 316-318.

(46) Helmy, R.; Wenslow, R. W.; Fadeev, A. Y. Reaction of organosilicon hydrides with solid surfaces: An example of surfacecatalyzed self-assembly. J. Am. Chem. Soc. 2004, 126 (24), 7595-7600.

(47) Collins, G.; O’Dwyer, C.; Morris, M.; Holmes, J. D. PalladiumCatalyzed Coupling Reactions for the Functionalization of Si Surfaces: Superior Stability of Alkenyl Monolayers. Langmuir 2013, 29 (38), 11950-11958. 